\title{
Editorial
}

\section{Special Issue Low Binder Concrete and Mortars}

\author{
Jorge de Brito ${ }^{1, *(1)}$ and Rawaz Kurda ${ }^{1,2, *}$ (i) \\ 1 Instituto Superior Técnico, Universidade de Lisboa, Av. Rovisco Pais, 1049-001 Lisbon, Portugal \\ 2 Department of Civil Engineering, Technical Engineering College, Erbil Polytechnic University, \\ Erbil 44001, Kurdistan-Region, Iraq \\ * Correspondence: jb@civil.ist.utl.pt (J.d.B.); rawaz.kurda@tecnico.ulisboa.pt (R.K.)
}

Received: 28 April 2020; Accepted: 28 April 2020; Published: 2 June 2020

\section{Introduction}

It is well known that, after water, concrete and mortars are the most demanded materials worldwide. Therefore, they have a significant influence on environmental impacts, namely because of their cement content. Thus, many alternative materials, such as supplementary cementitious materials, have been proposed to be used in order to decrease the environmental impacts of mortar and concrete. However, studies regarding extremely low binder content, namely cement, are still very scarce.

This Special Issue of Applied Sciences provides a forum for original studies and comprehensive reviews on the technical performance (e.g., mechanics and durability), economics and environmental impacts (e.g., global warming and energy consumption) of concrete and/or mortar containing low binder content. In other words, any attempts or techniques (i.e., using any type of supplementary cementitious materials, alkali activation (e.g., geopolymers), strengthening systems (e.g., fibers), by-product nano materials, additives, etc.) that help to decrease the cement content of concrete and mortars are welcome.

So far, 18 papers have been published in the Special Issue, of a total of 25 submitted. The next sections provide a brief summary of each of the papers published.

\section{Developing Zero-Cement Binder}

One way towards zero cement binder can be through the alkali activation technique. D'Elia et al. [1] studied the potential feasibility of the use of thermally pre-treated carbonate-high illite clay (LCR) as a precursor to produce alkali-activated paste. For that purpose, different activating solution concentrations $(4,6$ and $8 \mathrm{M} \mathrm{NaOH})$, with an alkaline solution/clay ratio of 0.55 , were used. In terms of cost and technical performance, the paste with $6 \mathrm{M} \mathrm{NaOH}$ solution can be considered an optimum concentration. Additionally, an aluminium-enriched C-S-H (C-A-S-H) gel of paste with a higher concentration (e.g., $6 \mathrm{M} \mathrm{NaOH}$ ) is less carbonated than that of the lower concentration. Furthermore, the output of this study showed that the LCR can be considered a potential material to be used in alkali-activated material with acceptable mechanical strength (20 and $30 \mathrm{MPa}$ at 2 and 28 days, respectively).

Šimonová et al. [2] enhanced the fracture properties of alkali-activated mortar made with slag by using steel microfibers. The effective crack model, work-of-fracture method and double-K fracture model were considered to evaluate the fracture properties of the mortar. This study concluded that the addition of $10-15 \%$ of the precursor's mass in microfibers is an optimum percentage to enhance the fracture properties of the alkali-activated mortar. For example, the fracture toughness and fracture energy values of the mortar increased by up to $50 \%$ and $250 \%$ with the addition of the steel fiber of $20 \%$, respectively. In addition, the compressive strength increased by up to $40 \%$ with the incorporation of the steel fiber of $10 \%$. 


\section{Ecotoxicological and Chemical Characteristics of the Non-Conventional Materials Used to Replace Cement and Natural Aggregates}

Concrete can be produced with low environmental impact and cost by incorporating some non-conventional binders and/or aggregates. Nevertheless, it may still not be considered a sustainable product due to its ecotoxicological issues. Thus, a study [3] evaluated the ecotoxicological potential of using fly ash (FA) and recycled concrete aggregates in concrete. In order to consider all aspects that relate to the toxicity, chemistry (non-metallic and metallic parameters) and ecotoxicology (battery of tests with the luminescent bacterium Vibrio fischeri, the freshwater crustacean Daphnia magna, and the yeast Saccharomyces cerevisiae) of eluates obtained from leaching, tests of raw materials and concrete containing FA and/or recycled concrete aggregates (RCA) were evaluated, and then compared to the limit values given by standards (non-hazardous or non-hazardous). The output of the results shows that, in terms of chemical characterization, although FA as a raw material can be classified as hazardous to landfill, concrete containing FA is classified as a non-hazardous material due to the solidification effect. In terms of ecotoxicity, although FA and RCA presented no or low levels of potential ecotoxicity, concrete with a high volume of FA and RA was classified as clearly ecotoxic, mainly due to Daphnia magna mobility.

\section{Reduce the Environmental Impacts and Resources Use of Binders}

As mentioned by Baghban and Mahjoub [4], reducing the environmental impacts and resource-use of binders are the key drivers for today's technology uptake. The mentioned study made a global review to show the feasibility of using non-conventional materials to reduce cement content and improve the durability of concrete. They show that limestone-calcined clay cement (LC3) is one of the promising binders that can be used in the concrete industry to improve mechanical performance, environmental impacts and cost. The authors then focused on another path to improve the performance of concrete containing LC3. This is due to the fact that concrete with high-performance characteristics leads to long service life, which is the main contributor to sustainability. For that purpose, they made an extensive literature review to see the effect of natural fibers, specifically "kenaf", on LC3 concrete, as a step toward green cementitious composite. They concluded that most mechanical (e.g., toughness, tensile strength and impact resistance) and durability (e.g., carbonation, sulphate and chloride resistance) properties can be enhanced compared to ordinary Portland cement concrete, specifically when the natural fiber is about $1 \%$ of binder's mass, with a length of about $50 \mathrm{~mm}$. The authors suggested using a combination of LC3 with natural fibers such as kenaf fiber due to the fact that the kenaf plant absorbs a significant amount of $\mathrm{CO}_{2}$ from the air.

Hu et al. [5] showed that cement content can be reduced by decreasing the porosity of the paste matrix. For that purpose, cement was replaced with different components and different grade tailings of waste limestone powder. Then, the specimens were characterized via nuclear magnetic resonance and scanning electron microscopy to understand their microstructure and pore properties. Based on the results, with a given grade tailing of the waste limestone powder, $20 \%$ of cement content can be replaced with limestone powder without jeopardizing the mechanical properties. Further, porosity, macropore proportion and the average pore radius decreased by $7 \%, 46 \%$ and $16 \%$, respectively.

As mentioned before, the durability of concrete can be an effective key factor to obtain sustainable concrete. Accordingly, Rehman et al. [6] studied the influence of the thermo-mechanical activation of bentonite on the mechanical and durability performance of concrete. For that purpose, they studied the mechanical (compressive and tensile strength) and durability (water absorption, sorptivity and acid attack resistance) properties of concrete containing different incorporation ratios $(10 \%, 15 \%, 20 \%$, $25 \%, 30 \%$ and $35 \%$ mass replacements of ordinary Portland cement) of bentonite that was thermally and mechanically activated. Apart from the fact that the environmental impacts of bentonite are way lower than those of ordinary Portland cement, specifically when mechanically activated, both the durability and the mechanical properties of the concrete mixes improved with the incorporation of 
bentonite in both activation techniques. The results also show that the incorporation ratio of bentonite of $15-25 \%$ is the optimum in terms of technical performance of concrete, and specifically for durability.

Hafez et al. [7] highlighted, through a systematic review of more than 300 peer reviewed articles, that the current methodology for environmental impact assessment of concrete is not conclusive. The reviewed values for the environmental impact of green concrete seemed to spread widely, with a mean quite close to that of ordinary Portland cement concrete mixes. Hence, the authors established five golden rules as a cornerstone for a standard concrete life cycle assessment methodology: (i) Include the whole life cycle, including the $\mathrm{CO}_{2}$ uptake throughout the service life; (ii) Develop a functional unit based on performance-based specifications of the concrete product; (iii) Rely on primary inventory data whenever possible; (iv) Combine several mid-point indicators; (v) Perform sensitivity and scenario analyses to tackle the intrinsic uncertainty of the data. The same authors [8] made another study to validate the optimization process of green concrete, based on the cost, environmental impacts and technical performance.

Narloch et al. [9] used an artificial neural network to establish a model for predicting the compressive strength of cement-stabilized rammed earth, using only scanning electron microscope images. The model showed reliable prediction results relative to other conventional methods, achieving $84 \%$ prediction accuracy without using a significant amount of materials to test the samples.

\section{Modify the Characteristics of the Cement-Based Materials}

Yeon [10] focused on the way to enhance the deformability of three-dimensional printable mortar containing FA and silica fume, using ethylene-vinyl acetate (EVA). Thus, they mainly focused on the effect of the EVA/binders ratio on the modulus of elasticity, drying shrinkage, and the thermal expansion of the mortar. The results show that as the EVA/binders ratio increased, the elastic modulus and compressive strength tended to reduce, and the opposite occurred for drying shrinkage and thermal expansion. Nevertheless, the maximum compressive strain seemed to increase. Accordingly, this path, specifically using a high EVA/binders ratio, is not advisable to enhance the deformability of three-dimensional printable mortar.

In another study, Fan et al. [11] also intended to improve the mechanical properties of mortar using approximately $0-2.0 \%$ (by cement's mass) polyvinyl alcohol (PVA). To understand the effect of PVA on the mechanical properties, hydration products and microstructure of the mortar, differential scanning calorimetry (DSC), Fourier transform infrared spectroscopy (FTIR) and scanning electron microscopy (SEM) results were obtained. They show that the optimum PVA content was $0.6 \%$ and $1.0 \%$ (by cement's mass) for the tensile and compressive strength of mortar. The authors explained that this is due to the fact that PVA formed evenly dispersed, network-like thin films within the cement matrix, and subsequently can act as bridges across microcracks and small voids to arrest cracking in the cement matrix.

Additionally, Park et al. [12] made a study under the title "experimental study on flexural behaviour of TRM-strengthened reinforced concrete (RC) beam: various types of textile-reinforced mortar with non-impregnated textile", and they showed the feasibility of strengthening RC beams using textile-reinforced mortar (TRM) with non-impregnated textile. The results show that the bearing capacity, strengthening efficiency and crack uniformity of beams can be improved with the use of TRM, especially when the mesh size of the textile was reduced and mechanical end anchorage implemented, and also when the textile lamination and textile reinforcement ratios increased.

Niu et al. [13] also attempted to modify the performance of the cement-based materials, namely concrete, using different types and combinations of fibers. For that purpose, the basalt fiber (BF) and polypropylene fiber (PF) were jointly and individually incorporated in concrete. The results show that the fibers can be beneficial to the compressive and tensile strength of concrete when a small percentage (each $0.05 \%$ of concrete's volume) of both fibers are jointly incorporated into concrete. The authors recommended using a high percentage of the fibers, but accurate control is necessary to disperse the 
fibers in the cement matrix. Similar to the performance of most fibers, PF and BF are more effective in enhancing tensile strength than compressive strength.

Yousuf et al. [14] made an extensive literature review to find a way to solve the issue of the crossover effect phenomenon in cement-based materials when they are subjected to accelerated initial curing. The higher curing temperature (e.g., $40-60^{\circ} \mathrm{C}$ ) may promote the cement matrix to rapidly create non-uniform hydration products, and subsequently generate a great porosity at later ages. The authors proposed using different types and incorporation ratios of cement-based materials to overcome this issue.

\section{Low Binder Concrete On-Site Application}

Apart from the production of the raw materials, the total environmental impacts and cost of cement-based materials also depend on the execution process. One way to promote this path can be with the three-dimensional printable technique. For example, Chen et al. [15] focused on the way to use non-conventional materials in the mentioned technique. Thus, they used high, medium and low grades (ratio of metakaolin) of calcined clay. They recommended the use of a high content of metakaolin in calcined clay because it considerably shortens the initial setting time, and increases the extrusion pressures and compressive strength at early and later ages. The same attempts can be seen in study [10] (Section 5).

\section{Sustainable Cement-Based Materials in Road Engineering}

Another way to reduce the consumption of natural aggregates is by reusing the existing pavement as aggregate. Gonzalo-Orden et al. [16] showed that this path has some uncertainty due to the fact that there is no specific test to determine the behavior of recycled pavements stabilized (full-depth reclamation-FDR) with cement. Thus, FDR with cement has been treated as cement-bound granular material or soil-cement. Since the bituminous material may be attached to the recycled pavement, the stiffness of the FDR with cement may be reduced. Therefore, this study intended to find long-term correlations between indirect flexural and tensile strength, and unconfined compressive strength in the FDR with cement, and to compare the outputs with the same relationships obtaining between soil-cement and cement-bound granular materials, in order to confirm whether their behaviors are similar or different; the latter was the case (the similar behavior hypothesis was not entirely accurate).

As in the previous study, the next ones $[17,18]$ also focused on sustainable road engineering. For that purpose, Liang et al. [17] recommended the use of a large amount of crushed construction waste, namely clay brick, to replace the fine aggregates of a cement stabilized macadam (CSM) subbase. The results showed that using $50 \%$ fine recycled clay aggregates is optimum for the CSM subbase. Du et al. [18] also studied the application of CSM. The authors confirmed the advantage of using sandstone in CSM, and that it can be used for road base construction.

Funding: This research received no external funding.

Acknowledgments: Thanks are due to all the authors and peer reviewers for their valuable contributions to this special issue. The MDPI management and staff are also to be congratulated for their untiring editorial support for the success of this project.

Conflicts of Interest: The authors declare no conflict of interest.

\section{References}

1. D’Elia, A.; Pinto, D.; Eramo, G.; Laviano, R.; Palomo, A.; Fernández-Jiménez, A. Effect of Alkali Concentration on the Activation of Carbonate-High Illite Clay. Appl. Sci. 2020, 10, 2203. [CrossRef]

2. Šimonová, H.; Frantík, P.; Keršner, Z.; Schmid, P.; Rovnaník, P. Components of the Fracture Response of Alkali-Activated Slag Composites with Steel Microfibers. Appl. Sci. 2019, 9, 1754. [CrossRef] 
3. Rodrigues, P.; Silvestre, J.D.; Flores-Colen, I.; Viegas, C.A.; Ahmed, H.H.; Kurda, R.; de Brito, J. Evaluation of the Ecotoxicological Potential of Fly Ash and Recycled Concrete Aggregates Use in Concrete. Appl. Sci. 2020, 10, 351. [CrossRef]

4. Baghban, M.H.; Mahjoub, R. Natural Kenaf Fiber and LC3 Binder for Sustainable Fiber-Reinforced Cementitious Composite: A Review. Appl. Sci. 2020, 10, 357. [CrossRef]

5. Hu, J.; Ding, X.; Ren, Q.; Luo, Z.; Jiang, Q. Effect of incorporating waste limestone powder into solid waste cemented paste backfill material. Appl. Sci. 2019, 9, 2076. [CrossRef]

6. Rehman, S.U.; Yaqub, M.; Noman, M.; Ali, B.; Khan, A.; Nasir, M.; Fahad, M.; Muneeb Abid, M.; Gul, A. The Influence of Thermo-Mechanical Activation of Bentonite on the Mechanical and Durability Performance of Concrete. Appl. Sci. 2019, 9, 5549. [CrossRef]

7. Hafez, H.; Kurda, R.; Cheung, W.M.; Nagaratnam, B. A Systematic Review of the Discrepancies in Life Cycle Assessments of Green Concrete. Appl. Sci. 2019, 9, 4803. [CrossRef]

8. Hafez, H.; Kurda, R.; Kurda, R.; Al-Hadad, B.; Mustafa, R.; Ali, B. A Critical Review on the Influence of Fine Recycled Aggregates on Technical Performance, Environmental Impact and Cost of Concrete. Appl. Sci. 2020, 10, 1018. [CrossRef]

9. Narloch, P.; Hassanat, A.; Tarawneh, A.S.; Anysz, H.; Kotowski, J.; Almohammadi, K. Predicting Compressive Strength of Cement-Stabilized Rammed Earth Based on SEM Images Using Computer Vision and Deep Learning. Appl. Sci. 2019, 9, 5131. [CrossRef]

10. Yeon, J. Short-Term Deformability of Three-Dimensional Printable EVA-Modified Cementitious Mortars. Appl. Sci. 2019, 9, 4184. [CrossRef]

11. Fan, J.; Li, G.; Deng, S.; Wang, Z. Mechanical Properties and Microstructure of Polyvinyl Alcohol (PVA) Modified Cement Mortar. Appl. Sci. 2019, 9, 2178. [CrossRef]

12. Park, J.; Hong, S.; Park, S.-K. Experimental Study on Flexural Behavior of TRM-Strengthened RC Beam: Various Types of Textile-Reinforced Mortar with Non-Impregnated Textile. Appl. Sci. 2019, 9, 1981. [CrossRef]

13. Niu, D.; Huang, D.; Zheng, H.; Su, L.; Fu, Q.; Luo, D. Experimental Study on Mechanical Properties and Fractal Dimension of Pore Structure of Basalt-Polypropylene Fiber-Reinforced Concrete. Appl. Sci. 2019, 9 , 1602. [CrossRef]

14. Yousuf, S.; Shafigh, P.; Ibrahim, Z.; Hashim, H.; Panjehpour, M. Crossover Effect in Cement-Based Materials: A Review. Appl. Sci. 2019, 9, 2776. [CrossRef]

15. Chen, Y.; Li, Z.; Chaves Figueiredo, S.; Çopuroğlu, O.; Veer, F.; Schlangen, E. Limestone and Calcined Clay-Based Sustainable Cementitious Materials for 3D Concrete Printing: A Fundamental Study of Extrudability and Early-Age Strength Development. Appl. Sci. 2019, 9, 1809. [CrossRef]

16. Gonzalo-Orden, H.; Linares-Unamunzaga, A.; Pérez-Acebo, H.; Díaz-Minguela, J. Advances in the study of the behavior of Full-Depth Reclamation (FDR) with cement. Appl. Sci. 2019, 9, 3055. [CrossRef]

17. Liang, C.; Wang, Y.; Song, W.; Tan, G.; Li, Y.; Guo, Y. Potential Activity of Recycled Clay Brick in Cement Stabilized Subbase. Appl. Sci. 2019, 9, 5208. [CrossRef]

18. Du, Q.; Pan, T.; Lv, J.; Zhou, J.; Ma, Q.; Sun, Q. Mechanical Properties of Sandstone Cement-Stabilized Macadam. Appl. Sci. 2019, 9, 3460. [CrossRef]

(C) 2020 by the authors. Licensee MDPI, Basel, Switzerland. This article is an open access article distributed under the terms and conditions of the Creative Commons Attribution (CC BY) license (http://creativecommons.org/licenses/by/4.0/). 